\title{
Rhoticity in Chinese English: An experimental investigation on the realization of the variant $(r)$ in an Expanding Circle variety
}

\author{
Zeyu Li \\ University of Münster \\ zeyu.li@uni-muenster.de \\ Barış Kabak \\ University of Würzburg \\ baris.kabak@uni-wuerzburg.de
}

\begin{abstract}
The realization of postvocalic / $\mathrm{r} /$ has been frequently examined in both diachronic and synchronic research on world Englishes, showing a multitude of linguistic and extra-linguistic factors to modulate the degree of rhoticity. Since rhoticity is one of the most important indices of variation across Englishes, it forms an instructive phonological marker to investigate the dynamics of norm formation in emerging varieties. While the Inner and Outer Circle varieties have been extensively studied, there is fairly little research on the variable realization of postvocalic $/ \mathrm{r} /$ in the Expanding Circle Englishes. Here, we fill this gap with a study on the degree of rhoticity by highly proficient users of an EFL variety emerging in China, college English teachers, who are pertinent norm providers for EFL learners. We provide a multivariate analysis of phonological and sociolinguistic factors conditioning the degree of rhoticity in Chinese English on the basis of speech production data from 13 participants. Results show that Chinese English is best categorized as marginally rhotic. Concerning the patterning of phonological variables, it aligns more with Inner Circle than Outer Circle Englishes, albeit with significant inter- and intra-speaker variability. We discuss the competing roles of norm orientation, substrate influence, and other relevant variables therein.
\end{abstract}

Keywords: Expanding Circle, Phonology, Rhoticity, EFL varieties of English 


\section{Introduction}

Due to their ambivalent phonetic properties, rhotic sounds are one of the most variable segments across the languages of the world, not only in their actual phonetic realization but also in their distribution within different word positions and phonological contexts. The abundance of empirical work on the realization of postvocalic $/ \mathrm{r} /{ }^{1}$ in English is a clear manifestation of the high degree of variability that this phoneme exhibits within individual speakers as well as across different speaker groups. Indeed, the presence or absence of postvocalic / $r$ / has long been considered one of the most salient features that robustly index dialectal differences in World Englishes (Trudgill and Hannah, 1994: 56). Broadly, accents of English that produce $/ \mathrm{r} /$ in syllable rhymes (also variably referred to as postvocalic $/ \mathrm{r} /$, coda $/ \mathrm{r} /$, or non-prevocalic $/ \mathrm{r} /$ ) are considered to be rhotic, whereas those that do not realize $/ \mathrm{r} /$ in this context are non-rhotic (Giegerich, 1992: 63). Accordingly, while non-rhotic accents pronounce $/ \mathrm{r}$ / only in syllable onsets as in red or break, rhotic accents would also produce the same category in the postvocalic position as in here and hurt. Despite this coarse distinction, rhoticity is known to be a gradient phenomenon. The classic work of Labov (1966) on New York City English, for instance, has shown that speakers go beyond the binary rhotic-nonrhotic distinction and instead show gradient patterns in their realization of postvocalic $/ \mathrm{r} /$. Along with grammar-external factors such as age, ethnicity, and socioeconomic background, Labov also demonstrated that grammar-internal phenomena such as stress and the following phonological environment crucially modulate the degree of rhoticity.

Several replications of Labov's groundbreaking study and its extensions to other varieties have not only yielded very similar patterns but also found additional factors such as the quality of the preceding vowel to be a predictor of the rate of rhoticity (see, for example, Fowler, 1986; Mather, 2012; Becker, 2009, 2014 for New York City English; Nagy and Irwin, 2007, 2010 for Boston English, and Feagin, 1990 for Alabama English). Furthermore, Labov's work showed that non-rhoticity as a historically prestigious variant in New York City has lost its prestige over time, adding lifespan dynamics to this variant. Such a dynamic approach has led to further work on other varieties of English, such as New Zealand English, where the loss of postvocalic / $r$ / was shown to be a gradual weakening process, but crucially progressing independently from the emergence of $/ \mathrm{r} /$-sandhi phenomena such as $/ \mathrm{r} /$-linking and $/ \mathrm{r} /$-intrusion (Hay and Clendon, 2012).

Apart from its importance in the field of sociolinguistics, the variant $(\mathrm{r})^{2}$ constitutes one of the most salient criteria that distinguish types of English around the globe (Trudgill and Hannah, 1994: 5-6) and its distribution in postvocalic position is considered to be "the most important phonotactic difference among accents of English" (Melchers and Shaw, 2003: 19). Thus, it may be possible to establish a phonological typology of World Englishes based on rhoticity if the (r) variant in each English variety were thoroughly studied. To date, rhoticity within Inner Circle Englishes (Kachru, 1982, 1985) has been well investigated in comparison to nonnative varieties of English. The non-rhotic varieties are found in most of England, Australia and New Zealand, whereas varieties elsewhere such as those found in Scotland, Ireland and most of the 
USA and Canada are predominantly rhotic (e.g., Giegerich, 1992: 63; Sundkvist and Gao, 2016: 43). A number of studies have documented a change toward more rhotic realizations in the Inner Circle areas, where the variant (r) has been historically unstable. For instance, a great deal of quantitative sociolinguistic research investigating (r) usage has shown that the historically prestigious non-rhoticity in various parts of the United States such as New York (Labov, 1966, 1972), Boston and New England (Irwin and Nagy, 2007), Philadelphia (Miller, 1998), and Upper Valley (Villard, 2009) has gradually lost its high social valuation.

While the variant (r) has attracted a great deal of interest also from the perspective of Outer Circle Englishes, as we will review below, there is very little on its nature and dynamics in Expanding Circle Englishes. We consider the latter types of English to constitute incipient non-native varieties that are on their way to establish their unique sociocultural stature and perpetuate novel norms within certain regions of the world. This paper aims to fill that gap with an empirical study on the degree of rhoticity in highly proficient nonnative users of an English variety emerging in China, which we will heretofore refer to as Chinese English. ${ }^{3}$. In particular, we will examine the nature and patterning of the variant (r) in the speech of English teachers, whom we assume to be one of the most pertinent norm providers for the learners of this variety. We will provide a multivariate analysis of phonological factors conditioning the degree of rhoticity in Chinese English and also explore the competing influence of extra-linguistic factors such as norm orientation, substrate influence, and other sociolinguistic variables therein. Our results take the debate on the dynamism of World Englishes to the dimension of growth. In its canonical sense, growth may refer to an increase in number, size, magnitude or value, and in the linguistic context we also consider it to be a result of a process of acquisition, reinterpretation and extension of existing linguistic schemes and patterns that may yield seemingly "novel" patterns of behavior. These novel patterns are however very likely to be conditioned by factors that underlie language acquisition processes and language change. To that end, we will discuss the consequences of our findings in the framework of the Dynamic Equational Model (Kabak, to appear), which views sound systems as empirical constructs at any point and type of language evolution (e.g., first/ second language acquisition, language attrition, diachronic and synchronic variation, in the emergence of varieties, etc.) and aims to unite these different types of sound evolution as being governed by similar laws, thus considering them equally complex and natural.

The paper is organized in the following way. In Section 2, we will review findings from previous research concerning the nature of rhoticity in Inner Circle (2.1), Outer Circle (2.2.), and Expanding Circle Englishes (2.3) in an attempt to lay ground for the present study. Section 3 provides a phonological characterization of rhoticity in the substrate language in question, Mandarin Chinese. We present the design features of our study, data elicitation procedures, and our experimental conditions in Section 4, followed by our multivariate analysis of the results in Section 5. Section 6 unpacks the linguistic and extra-linguistic variables that turned out to be significant factors in the present study against the background of previous studies on the variant (r). Section 7 
concludes with the general implications of the findings for the evolution of sound systems with some suggestions for future research.

\section{The variant (r) in Englishes around the globe}

We adopt the framework of Kachru $(1982,1985)$ in our classification of World Englishes, whose approach resonates with our interest in the developmental aspects and the genesis of new norms in localized varieties of English. While this framework may fail to reflect some of the dynamic changes that have taken place especially in Inner Circle Englishes through time (see The Dynamic Model of Schneider 2003, 2007), its social, political and practical implications on the conceptualization of growing EFL users around the globe remain well-founded. According to Kachru, the first circle is called "the inner circle", which is located at the center of the concentric model and contains countries where English is spoken as native language, such as America, Britain, Australia, New Zealand, and Canada. The second group is "the outer circle". It surrounds the inner circle and comprises places where English is used as a second language such as Singapore, India, Tanzania and Kenya, etc. The biggest group is "the expanding circle", which includes countries such as Korea, China and Germany that use English as a foreign language. Given that most systematic studies on rhoticity have so far focused on Inner Circle Englishes, some of which we outlined above, below we focus on Outer and Expanding Circle Englishes. Needless to say, there is also a considerable amount of work on the variant (r) from the perspective of social and ethnic variation, focusing for example on African American English in different regions of the United States (see Thomas, 2007: 453-454 for a review). Furthermore, a few other factors have recently been shown to predict the degree of rhoticity in varieties of English such as the topic of conversation and exposure to a (non)rhotic variety (Love and Walker, 2012) as well as style shift (Eberhard and Downs, 2015). Since our primary aim here is to put the variant ( $\mathrm{r}$ ) on a more global perspective and to study the genesis of phonological repertoires in newer forms of English in regions with greater masses of EFL learners, we will not cover socioethnically and pragmatically modulated rhoticity here.

\subsection{Rhoticity in Inner Circle Englishes}

In order to pinpoint those factors that are time and again deemed important in the investigation of the variable nature of rhoticity, here we will discuss recent research on two Inner Circle Englishes, one from the United States and the other from the United Kingdom.

Nagy and Irwin (2010) investigated the realization of (r) in English spoken in Boston and two New Hampshire (NH) towns and described the effects of both internal and external variables on (r) usage by 55 participants. The study has shown that the preceding vowel and variation in geography, ethnicity, and age significantly influence the presence or absence of (r) in Boston and the two NH towns. It has also been suggested that English in these areas is gradually gaining rhoticity as younger speakers 
were found to be more rhotic than older speakers. We consider Nagy and Irwin (2010) representative and comprehensive in its kind because it additionally provides an indepth comparison of studies of (r) in North American English and introduces a method to compare the quantitative amount of variation between communities. More precisely, Nagy and Irwin explored certain factors that have repeatedly emerged as relevant to all rhoticity variation studies in the United States and turned to a comparison of variationist studies of (r) across North America to report on the relative universality and dissimilarity of these different factors.

Piercy (2012) presented a similar line of research concerning rhoticity in Dorset English, a variety from the Southwest of England that is originally rhotic. This study has focused on, among other linguistic factors, extra-linguistic factors such as age and gender that are considered to condition (r). An experiment based on 24 native speakers from Dorset showed that this historically rhotic variety in England has been gradually losing its rhoticity as evidenced by the decrease in the frequency of (r) tokens in both real and apparent time. While Piercy found a strong correlation between age and (r) in apparent time, a real time point of comparison to the Survey of English Dialects (SED) showed a steep decline of the overall (r) frequency from $97 \%$ in the SED to $29 \%$ in her study. Furthermore, the preceding vowel, word context, stress and lexical frequency constituted significant linguistic factors controlling (r) in her study. Piercy (2012: 8384) further provided a transatlantic cross-dialectal comparison to see whether varieties losing or gaining rhoticity are influenced by the universal linguistic constraints. In particular, the results from the Dorset English study were compared with those from Nagy and Irwin (2010), showing that there are similarities in the linguistic contexts that determine the presence/ absence of $/ \mathrm{r}$ / irrespective of whether an Inner Circle variety is gaining or losing rhoticity (Piercy, 2012: 85).

The following review of studies will only be cursory to view the variant (r) from a more global and typological perspective. We will recapitulate some of the factors that were consistently shown to be relevant for the variant (r) in our methodology section in order to motivate the design features of our study and highlight some predictions.

\subsection{Rhoticity in Outer Circle Englishes}

With regard to the Outer Circle (Kachru, 1982, 1985), it is more challenging to give an explicit statement on the nature and extent of rhoticity (Melchers and Shaw, 2003: 131). In general, varieties that are traditionally considered to be predominantly rhotic are Indian English (Wells, 1982, but see below), Pakistani English (Mahboob and Ahmar, 2004), Maltese English (Bonnici, 2010), and Philippine English (Llamzon, 1997) while other regions are considered to be mostly non-rhotic, including Hong Kong (Setter et al., 2010), Malaysia and Singapore (Deterding, 2007) in Asia, East African countries like Kenya and Tanzania (Schmied, 2006), and West African countries such as Nigeria (Gut, 2004). However, Melchers and Shaw (2003: 131) point out that there has been little agreement on whether a particular variety in the Outer Circle is rhotic or not, since the depiction of a particular English variety on the grounds of rhoticity could be sensitive to a variety of endogenous and exogenous factors, as shown by previous 
research. For example, Salbrina and Deterding (2010) reported that Singapore English was mostly non-rhotic, with only $8.3 \%$ of their test tokens showing rhoticity. In contrast, the earlier work by Tan and Gupta (1992) revealed some degree of rhoticity in Singapore English, and further demonstrated that the $/ \mathrm{r} /$-fullness is a prestigious feature for some Singaporeans. Poedjosoedarmo (2000), as cited in Tan (2012: 2), also suggested that American English-like characteristics were found in Singapore English; however, very few realizations of ( $r$ ) have been noted in the database. In a similar vein, Tan (2012: 12-13) argued that speakers of higher education levels and socioeconomic status have a tendency to produce more (r)s (55.9\%), compared to speakers from lower social class and education background $(10.32 \%)$. Tan further suggested that her results seem to follow the classic Labovian hypothesis (Labov 1966) on the use of (r) by speakers from different social stratifications in New York City (Labov, 1966). According to Tan, this kind of ambivalence with regard to the degree of rhoticity in Southeast Asian Englishes is universal.

Considering the complex sociolinguistic circumstances surrounding the Outer Circle, Melchers and Shaw (2003: 131) have argued that there are five major factors exerting potential influence on the rhoticity in postcolonial Englishes. These are: substrate influence, education, source language, model, and endonormativity. To begin with, the substrate influence factor predicts that if sequences such as $V r C$ or $V r \#$ do not exist in the substrate language of a particular country, this will weigh against rhoticity. In contrast, substrate languages that allow such structures (e.g. Indian languages and Malay) would favour rhoticity. As for education, Melchers and Shaw (2003: 131) indicated that school learning would tend to produce pronunciation patterns reflecting the orthographic representation of sounds in spelling. In terms of endonormativity, English varieties introduced by speakers from England are expected to show a tendency to be non-rhotic while those instituted by Americans or speakers from Scotland and Ireland will tend to be rhotic. Likewise, the pronunciation patterns of individuals that act as speech models such as teachers and speakers in the local mass media would be very likely to influence the outcome. The local attitude, in addition, also plays an important role in determining the degree of rhoticity. It is claimed that if the local attitude in a particular region is highly endonormative, speakers would be more likely to speak in the local way conditioned by the above-mentioned factors, whereas a relatively exonormative attitude would lead to an accent that is closer to the dominant American pattern.

A number of studies on rhoticity in Outer Circle Englishes investigated the complex interplay of the above-mentioned five factors as well as other determinants. For instance, Chand's (2010) research on the usage of (r) in urban Indian English illustrated a diachronic change in the degree of rhoticity across three generations. Despite earlier claims that Indian English is a rhotic dialect (Wells, 1982: 629), only the oldest generation in Chand's data was found to be mostly rhotic. While speakers of the working generation preferred to speak non-rhotic English, the youngest generation tended to be more rhotic at home yet non-rhotic in formal situations. Several sociolinguistic factors have been shown to be influential in shaping the development of 
rhoticity in this variety such as distinctive postcolonial history, governmental policy, joint family system, change of instruction languages in school, linguistic attitude and various media inputs. Chand (2010: 22-25) has suggested that the oldest generation in the pre-partition India appeared to be more rhotic due to the influence from the rhotic substrate language and multiple prestige targets. She showed that the younger working generation, in contrast, tended to be non-rhotic, since the target pronunciation in India was narrowed to Received Pronunciation (RP) after Partition. Non-rhotic accent was also used as the official instruction language in school. Interestingly, the current youth were found to be mostly rhotic and speak like their grandparents at home owing to the joint family system but switched to RP in the formal speech context like their parents.

Similar research has been conducted by Bonnici (2010) on Maltese English, who drew her data from sociolinguistic interviews with 32 (16 male and 16 female) English dominant or balanced Maltese-English bilinguals from Malta, ranging in age from 18 to 81. The results of this study have demonstrated an apparent time change in progress, with a move from extremely $/ \mathrm{r} /$-full behavior to $/ \mathrm{r} /$-lessness and back to increased $/ \mathrm{r} /-$ fullness. This tendency in Maltese English is found to be subject to multiple sociolinguistic constraints such as dramatic shifts in speakers' exposure to rhotic varieties, local stigmatization of salient features of RP, as well as the rhotic structure of the substrate language, Maltese.

Hartmann and Zerbian (2010) explored rhoticity in the speech of black speakers of South African English, investigating whether the degree of rhoticity in South African English is sensitive to gender and socioeconomic stratification. Using various elicitation tasks (e.g., reading a disclaimer, answering simple questions with "better" or "worse", etc.), Hartmann and Zerbian conducted 39 interviews with both male and female native black South African participants. The two gender groups were further classified into more and less affluent categories (see Hartmann and Zerbian, 2010: 138-139 for the criteria). It was shown that rhoticity in Black South African English is predominantly a female phenomenon. While the degree of rhoticity was the highest among rich South African female participants (38\%), "the less affluent females showed rhoticity in $18 \%$ of the cases on average" (p. 140). Interestingly, while $90 \%$ of all the affluent females in their sample displayed some degree of rhoticity, the mean rate of rhoticity was $8 \%$ among the affluent males, with only $40 \%$ of such participants showing a small amount of rhoticity (which included even the use of linking-r). However, none of the less affluent male participants showed any $/ \mathrm{r} /$ presence. This result was attributed to the fact that there is a covert prestige for African men to use their African languages. Accordingly, Hartmann and Zerbian (2010: 139-140) have concluded that their research provides evidence that both gender and affluence determine the degree of rhoticity in Black South African English and suggested that black female speakers are more progressive in their language use than black male speakers, as mirrored, for instance, by their more frequent use of English with their peers and family (p. 144). It should be noted however that their study overlooks the phonological aspects of rhoticity within this historically non-rhotic English variety.

\subsection{Rhoticity in Expanding Circle Englishes}


In contrast to other types of English, the variant (r) in Expanding Circle Englishes is severely understudied. At the point of writing this paper, we encountered only two relevant studies, one on Korean English (Kang, 2013) and another on Yunnan English (Sundkvist and Gao, 2016), both of which we will unpack below.

Based on an empirical study with a test sample of 30 college students from Korea, Kang (2013) reported that the Korean variety of English is more rhotic and closer to American English. Meanwhile, both internal and external constraints controlling the variable (r) were explored. Kang's results showed that the external variables outweigh internal factors and exert a greater impact on rhoticity in Korean English (e.g., speech style, English-speaking nation living experience, proficiency level, and sex). Two limitations about this research were reported by Kang. First, the experiment in this study was exclusively based on reading speech, with the passage reading task as the task to elicit informal speech style and the word-list reading task to elicit less informal speech. Variation in speech styles, however, could not be well demonstrated by the two tasks that relied on reading. What is necessary here is spontaneous speech to uncover any potentially task-induced variation. The other limitation, according to Kang, concerns the age of speakers. Since only young college students were recruited as informants, age could not be examined as a potential external factor. Thus, Kang suggested that older speakers should be employed in the future research.

Sundkvist and Gao's (2016) study on 'Yunnan English' also explores the nature of rhoticity in Expanding Circle Englishes, in which 8 college students from Yunnan province in China were presented with various tasks representing three different speech styles. Their results showed that the most informal interview task displayed the lowest degree of (r) presence $(38.5 \%)$, followed by the reading task with a slightly higher percentage (45.1\%). The highest rate of rhoticity $(64.9 \%)$, however, came from the most formal questionnaire task. Accordingly, Sundkvist and Gao (2016: 55) concluded that the variation in speech styles is influential to rhoticity in this nonnative variety due to various levels of formality and attention triggered by the tasks. Their work, according to Sundkvist and Gao (2016), has added to the limited empirical work on the rhoticity of English in the Expanding Circle. Furthermore, it has extended the inquiry into styletriggered variation, on which little work has so far been published. However, various potential linguistic and non-linguistic constraints on rhoticity in the Yunnan variety of Chinese English were not systematically controlled for. Additionally, the researchers do not discuss the potential contribution of L1 rhoticity. As we will see below, the Yunnan variety of Mandarin Chinese is largely non-rhotic just like many Mandarin varieties spoken in the South. Since all of the 8 participants spoke this dialect, it is not possible to tell whether Chinese English speakers with more rhotic backgrounds (such as those from North China) would also exhibit this type of variation that is commensurate with different degrees of formality. Finally, it should be noted that, as in Kang's (2013) study, this study drew its findings from test groups comprised of students.

\subsection{Motivating the Present Study}


While studies on EFL learner groups may echo properties of incipient EFL learner varieties, we find it necessary to investigate an Expanding Circle English from the point of view of the formation and perpetuation of endonormative practices in the Expanding Circle. To that end, it is essential to investigate a group of EFL users comprised of highly proficient speakers who use English regularly in their daily lives and who serve as models for incoming users of English in their locality-English teachers. ${ }^{4}$ Furthermore, since it remains to be a challenge to determine whether an English variety is rhotic or not due to the multitude and complexity of factors, studies that take into account both language-external and language-internal variables are necessary to gain a comprehensive understanding of rhoticity in Expanding Circle Englishes. Given the fact that there are very few studies on this phonological variable within this relatively understudied type of English, here we aim to examine the degree of rhoticity in one of the most prominent varieties in the Expanding Circle, Chinese English, with special emphasis on both the endogenous and exogenous constraints affecting the variable realization of (r). In particular, we test whether Chinese English is rhotic or non-rhotic in light of the phonological constraints that were previously reported to affect variation in ( $r$ ) in Inner Circle Englishes. We also examine the role of extra-linguistic factors such as target norm and L1 rhoticity influencing Chinese English rhoticity.

\section{Substrate influence: Rhoticity in Mandarin Chinese}

Rhoticity in the substrate language of a particular English variety has been considered a significant factor influencing the variable (r) in English (Melchers and Shaw, 2003), which makes it necessary for us to discuss the nature of rhoticity in the relevant substrate language of our Chinese English group, Mandarin Chinese.

Due to the severe restrictions on the type of consonantal segment that can occur in the postvocalic position (Ching 1973, Hansen 2001), postvocalic rhoticty in Mandarin Chinese is mainly attributed to the use of the suffix $/ \partial /$ ( $/ L$ in simple Chinese character), which is a distinguishing characteristic of the Beijing dialect that is widely used in China. According to Duanmu (2007: 223-224), many Chinese dialects in the Mandarin family have this diminutive rhotic retroflex suffix, which is mostly used in North China. Mandarin spoken in the South of China, in contrast, is predominantly nonrhotic and most Southern Chinese dialects such as Cantonese and Hokkien also do not have rhotic accents at all.

The analysis of $/ \mathfrak{z} /$-colored syllables in Mandarin is not straightforward. Duanmu (2007: 224) assumes that the rhotic suffix is underlyingly specified only for the features Coronal and [+retroflex], which then merges with the host syllable that it attaches to. Two main merging processes are reported. First, if the sounds in the host rhyme are incompatible with [+retroflex], such as /n/,/i/, and /y/, they would either be replaced by $/ \partial /$ or pushed into the onset. For instance, when the rhotic suffix attaches to [p ${ }^{h}$ an] 'plate', it is realized as [ $\mathrm{p}^{\mathrm{h}} \mathrm{a} \boldsymbol{\gamma} \mathrm{r}$, whereby $/ \mathrm{n} /$ is replaced by $/ \boldsymbol{\gamma} /$. When the same suffix is 
attached to [y] 'fish', the rhyme is pushed into the onset, yielding [บәə]. Elsewhere the suffix is simply added to the coda position or merged with the syllable it attaches to (e.g., $\left[\mathrm{x}^{\mathrm{w}} \mathrm{aa}\right]$ "flower" $\rightarrow\left[\mathrm{x}^{\mathrm{w}} \mathrm{a}\right.$ r $]$ ). In all of these cases, the stems affixed by the rhotic suffix are rendered rhotic.

According to Chen (1999: 34-41), the rhotic suffix in Mandarin Chinese is mainly used in one of the following three situations. Firstly, it may serve to semantically

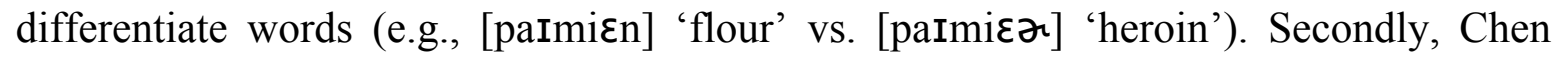
argues that many Mandarin words habitually occur with the rhotic suffix in North China, while their non-rhotic counterparts, despite acceptable, would sound unnatural to rhotic speakers. For example, [ $\left.\mathrm{x}^{\mathrm{w}} \mathrm{aa}\right]$, which means 'flower', is usually produced as $\left[\mathrm{x}^{\mathrm{w}} \mathrm{a} \boldsymbol{2}\right]$ by rhotic Mandarin speakers while being realized primarily as $\left[\mathrm{x}^{\mathrm{w}} \mathrm{aa}\right]$ by the non-rhotic speakers from the South China. Another important fact about the rhotic suffix in Mandarin involves the stylistic effect it achieves. In particular, Chen argues that the rhoticized form in Mandarin is typically confined to informal situations, while the corresponding unrhoticized form is used more frequently in formal speech contexts. This style-dependent variation can be taken to suggest that the degree of rhoticity in English for a particular rhotic Mandarin speaker is likely to vary significantly across different speech styles. For example, casual speech produced by a rhotic Mandarin speaker is likely to be colored by an abundance of rhotic sounds, increasing the likelihood of $/ \mathrm{r}$-fullness, whereas this rate may decline in the same speaker when delivering a speech in a more formal situation. We take into account this potential stylistic effect in our experiment.

\section{Methodology}

\subsection{Participants}

Thirteen speakers ( 8 female, 5 male) from China were recruited for the present study. All of them were college English teachers at the North China Institute of Science and Technology (NCIST), a university that is located in the east of Beijing. We elicited participant-internal and demographic data by way of a questionnaire (see the appendix), which revealed the following characteristics. Despite its location in North China, informants of the present study were of various provinces of origin in China. All were native Mandarin speakers, aged between 31 and 59. Ten of them reported to speak particular Chinese dialects besides Mandarin due to their place of origin (the remaining 3 did not self-report any dialectal background). In addition, all of them used English as their first foreign language, with the knowledge of different additional foreign languages with varying levels of proficiency. It is worth noting that none of their additional foreign languages is rhotic. While 7 of them reported to use General American English as their target norm, 6 speakers preferred Received Pronunciation (RP), which provided us with a balanced set insofar as testing the contribution of L1 
rhoticity. In addition, none of them had been staying abroad in an English-speaking country for more than a month. All the participants were tested at NCIST in China. The background statistics of the informant set is summarized in Table 1.

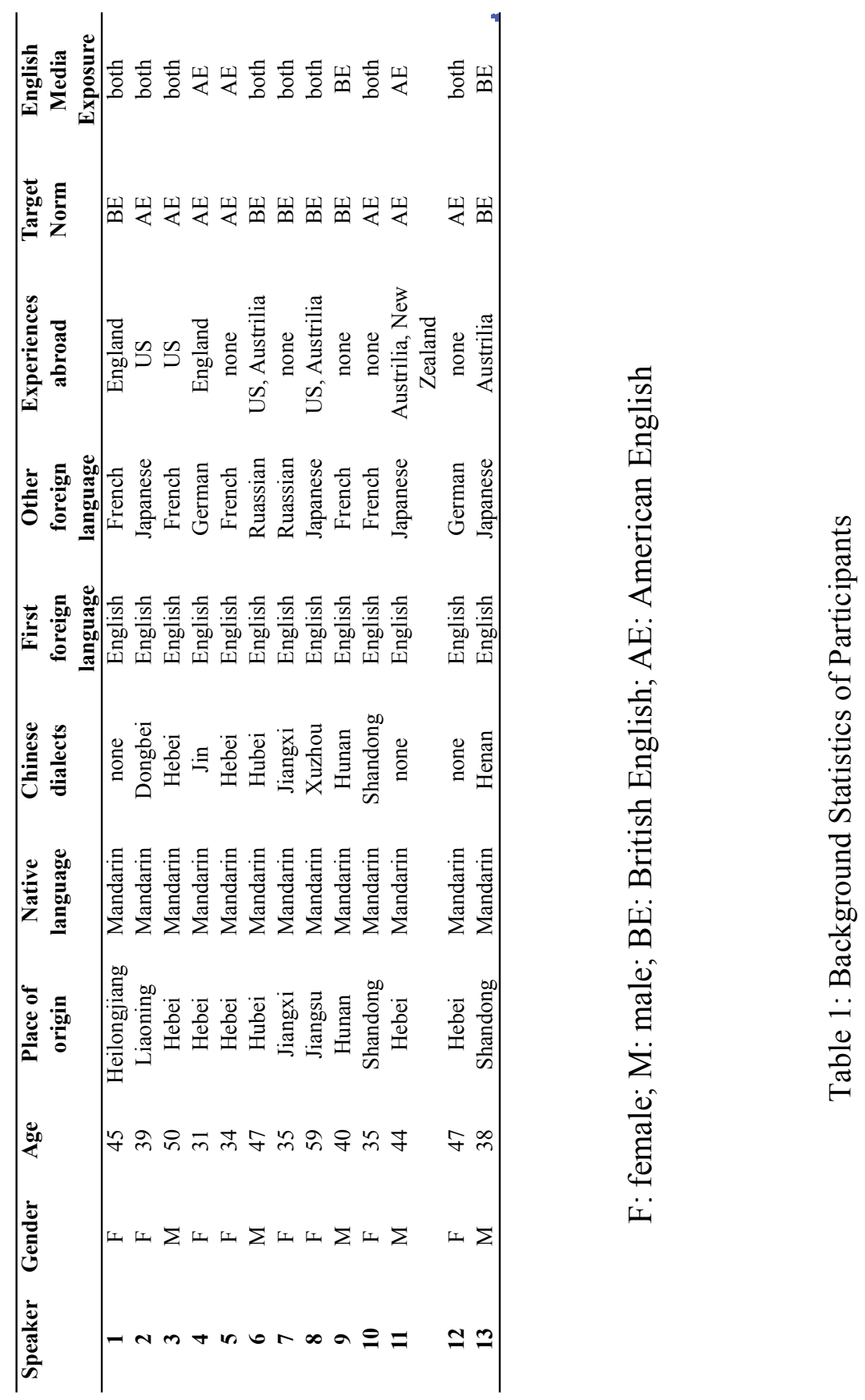




\subsection{Data collection}

The elicitation of speech data in the present study consisted of three tasks: 1) a reading aloud task, where the participants were given a short story in English, 2) a free speech task in English, and 3) a reading aloud task in Mandarin Chinese, which were administrated in this particular order for all participants. All participants were recorded in an acoustic laboratory at the NCIST individually using a high-quality microphone (NUEMANN U87). The speech was digitalized onto a computer (Apple Mac Pro $\mathrm{MC} 561 \mathrm{CH} / \mathrm{A}$ ) at a sampling rate of $48000 \mathrm{~Hz}$.

The reading task in English enabled us to collect fixed speech data by controlling for the speech style, test tokens, and linguistic environments. For this, we used a short English text, The Wolf Passage, an adaptation of Aesop's fable "The Boy who Cried Wolf" by Deterding (2006). This passage was specifically designed to elicit phonetic data in English and is claimed to contain clear tokens of all the vowels and consonants of English (Salbrina and Deterding, 2010). Besides, it includes certain low frequency phonemes that were found to be particularly relevant in the research of Asian Englishes (Sundkvist and Gao, 2016). We employed two additional paragraphs that are thematically related to the fable to generate a balanced design in order to test various phonological conditions that have been previously deemed important (the quality of the preceding vowels and the type of syllable structure). Altogether the reading task yielded 36 test tokens, testing 6 different vowel categories and 2 different syllable structures (Table 2).

\begin{tabular}{|c|c|c|c|c|c|c|}
\hline & NURSE & LETTER & NEAR & SQUARE & NORTH & START \\
\hline $\begin{array}{c}/ \mathbf{r} / \text { in Coda } \\
\text { position }\end{array}$ & $\begin{array}{l}\text { emergency } \\
\text { version } \\
\text { perfect }\end{array}$ & $\begin{array}{c}\text { pleasure } \\
\text { however } \\
\text { louder }\end{array}$ & $\begin{array}{c}\text { near } \\
\text { nearby } \\
\text { appear }\end{array}$ & $\begin{array}{c}\text { there } \\
\text { air } \\
\text { where }\end{array}$ & $\begin{array}{c}\text { more } \\
\text { unfortunately } \\
\text { before }\end{array}$ & $\begin{array}{c}\text { farmers } \\
\text { hearted } \\
\text { far }\end{array}$ \\
\hline $\begin{array}{c}\text { /r/ in } \\
\text { Consonant } \\
\text { Clusters }\end{array}$ & $\begin{array}{c}\text { heard } \\
\text { concern } \\
\text { third }\end{array}$ & $\begin{array}{l}\text { southern } \\
\text { shepherd } \\
\text { villagers }\end{array}$ & $\begin{array}{c}\text { weird } \\
\text { appeared } \\
\text { years }\end{array}$ & $\begin{array}{c}\text { scared } \\
\text { impaired } \\
\text { repaired }\end{array}$ & $\begin{array}{l}\text { short } \\
\text { course } \\
\text { warm }\end{array}$ & $\begin{array}{c}\text { dark } \\
\text { alarm } \\
\text { harmful }\end{array}$ \\
\hline
\end{tabular}

Table 2: Stratification of test tokens by preceding vowel and syllable structure in reading task

After reading aloud the passage, the participants were given a free speech task, in which an approximately five-minute talk around the suggested themes was expected. In particular, they were asked to select one or two topics from the following six options: food, sports, Internet, weather, marriage, music, and festival, and then to talk about it or answer relevant questions for approximately five minutes. Given that a number of studies have shown that variation in speech styles significantly influence the performance of English speakers (e.g. Labov, 1972; Irwin and Nagy, 2010; Sundkvist and Gao, 2016) and that the rhotic suffix in Mandarin is assumed to be more frequent in colloquial language, we asked whether this type of a task would reveal differences in the amount of rhoticity in comparison to a more formal reading task. 
In order to examine speakers' degree of rhoticity in their native language, which is imperative to the investigation of potential cross-language influence effects on the realization of (r), we additionally asked speakers to read aloud a Mandarin sentence that contained 10 common words that are typically rendered with rhotic vowels in rhotic varieties of Mandarin. The rhotic suffix ' $L$ ' in Mandarin Chinese was not presented in the text to avoid the potential impact of orthography. The assumption was that rhotic Mandarin speakers were expected to produce rhotic sounds at the end of these words habitually, regardless of whether the rhotic suffixes were in the text or not.

Following the recording session, informants filled out a demographic questionnaire, in which information about their personal background and the preferred English variety was collected (see the appendix). The final part of the questionnaire involved 10 statements about RP and American English (e.g., "British English /r/-less accent conveys a sense of arrogance.") to allow for a more implicit measure of the participant attitudes to verify their preferred variety. Here, the participants were asked to indicate their degree of agreement or disagreement on a 5-level Likert scale. The measures ranged from a strong preference for non-rhoticity (score of 1) to a definite partiality for rhoticity (score of 5), with a neutral opinion falling on 3. As a result, we assumed that a final score higher than 30 would show an American rhotic English preference, while lower than 30 displays an inclination for a British non-rhotic accent. All the information provided in the present study was self-reported by the informants. Since the questionnaire contained questions revealing the purposes of the study, such as speaker's target norm and attitude toward rhoticity, which may bias the participants' accentual behavior before the recording sessions, this task was administered as the last step in the experiment.

\subsection{Data coding}

A total of 762 tokens for 13 speakers were elicited in the two English tasks of the experiment. The tokens did not include the cases that potentially give rise to linking $/ \mathrm{r} /$, where postvocalic (r) ordinarily surfaces due to the following vowel-initial word in most non-rhotic varieties. A binary choice was made between the presence and absence of the (r) variant for each token through perceptual inspection by the first author, who is phonetically trained. An additional phonetically-trained listener checked a subsample of the tokens $(n=200)$, which returned a high degree of inter-rater reliability $(94 \%$ agreement).

Alongside the presence or absence of (r), each test token was also coded for the independent variables that have been examined in studies of rhoticity elsewhere and shown to be influential in order to facilitate the comparability of the present research with others. Furthermore, extra-linguistic factors that were expected to affect the production of (r) in Chinese English were also grouped and analyzed. Below, we will unpack each.

\subsubsection{Social factor groups}


Speakers of the present study came from 8 different provinces of China, which represents a broad spectrum. Apart from place of origin, we identified 9 other potential demographic and speaker-specific variables: age, gender, language attitude, target norm, L1 Mandarin rhoticity, speech style, media exposure, additional language(s) spoken by the informants, and experience abroad and tested whether they determine postvocalic / $/ \mathrm{r}$ presence in Chinese English. Table 3 summarizes the distribution of these extra-linguistic variables in our test group.

\begin{tabular}{|c|c|c|}
\hline Factor Group & Factors/Criteria & $\begin{array}{l}\text { Number of } \\
\text { Participants }\end{array}$ \\
\hline \multirow[t]{2}{*}{ Age } & Older group ( $>45$ years old) & $5 / 13$ \\
\hline & Younger group ( $\leq 44$ years old $)$ & $8 / 13$ \\
\hline \multirow[t]{2}{*}{ Gender } & Male & $5 / 13$ \\
\hline & Female & $8 / 13$ \\
\hline \multirow{2}{*}{$\begin{array}{l}\text { Language } \\
\text { Attitude }\end{array}$} & American English (score in the attitude survey $\geq 30$ ) & $7 / 13$ \\
\hline & British English (score in the attitude survey $<30$ ) & $6 / 13$ \\
\hline \multirow[t]{2}{*}{ Target Norm } & American English & $7 / 13$ \\
\hline & British English & $6 / 13$ \\
\hline \multirow{2}{*}{$\begin{array}{l}\text { Rhoticity in } \\
\text { Mandarin }\end{array}$} & Nonrhotic ( $>80 \%$ non-rhotic in Mandarin reading task) & $8 / 13$ \\
\hline & Rhotic & $5 / 13$ \\
\hline \multirow{2}{*}{$\begin{array}{l}\text { Place of Origin } \\
\text { in China }\end{array}$} & North & $10 / 13$ \\
\hline & South & $3 / 13$ \\
\hline \multirow[t]{2}{*}{ Speech Style } & Reading & all speakers \\
\hline & Free Speech & all speakers \\
\hline \multirow{3}{*}{$\begin{array}{l}\text { Regular English } \\
\text { Media Exposure }\end{array}$} & American English & $3 / 13$ \\
\hline & British English & $2 / 13$ \\
\hline & Both & $8 / 13$ \\
\hline $\begin{array}{l}\text { Languages } \\
\text { Spoken }\end{array}$ & ie. Russian, German, Japanese, etc. & see Table 1 \\
\hline Experience & ie. New Zealand, Austrilia, US, etc. & see Table 1 \\
\hline
\end{tabular}

Table 3: Summary of external factors

It should be noted that since age and gender differences in rhoticity may be more directly related to the sociohistorical sphere surrounding ESL contexts and the sociolinguistic identities and ideologies therein, these factors are more likely to play a role in Outer Circle Englishes (e.g., Chand, 2010 for Indian English, Hartmann and Zerbian 2010 for Black South African English) than in Expanding Circle Englishes. ${ }^{5}$ However, we expected speech style to be a more conspicuous predictor of $/ \mathrm{r} /$ presence in Chinese English especially given that both studies on Korean English (Kang, 2013) and Yunnan English (Sundkvist and Gao, 2016) have shown that different speech contexts would trigger various levels of attention, thus resulting in variation in rhoticity in Expanding Circle Englishes. Furthermore, as mentioned above, the variable nature of rhoticity depending on speech style in rhotic varieties of Mandarin Chinese motivated 
us to include this factor as a predictor. The remaining factors, language attitude, native language rhoticity, media exposure, additional languages spoken, and experience abroad potentially account for variation in the realization of (r) according to Melchers and Shaw (2003).

\subsubsection{Linguistic factor groups}

Apart from above-mentioned sociolinguistic factors, phonological constraints have been considered to be influential to (r) as well (e.g. Irwin and Nagy, 2007; Piercy, 2012). Here we focus on 3 phonological variables that are found to be the most robust predictors in various research on rhoticity: preceding vowel, stress and syllable structure. Table 4 lists the factor groups and individual subfactors with an example for each.

\begin{tabular}{|l|l|l|}
\hline Factor Group & Factors & Example \\
\hline Preceding Vowel & NURSE & emergency \\
\cline { 2 - 3 } & LETTER & pleasure \\
\cline { 2 - 3 } & NEAR & nearby \\
\cline { 2 - 3 } & SQUARE & scared \\
\cline { 2 - 3 } & FORCE & before \\
\cline { 2 - 3 } & START & alarm \\
\hline Syllabic Stress & Stressed & version \\
\cline { 2 - 3 } & Unstressed & southern \\
\hline Syllable Structure & Coda & perfect \\
\cline { 2 - 3 } & Consonant Clusters & shepherd \\
\hline
\end{tabular}

Table 4: Summary of internal constraints

In terms of the preceding vowel, each test token was coded adopting the citation form of Wells' lexical sets (Wells, 1982). To ensure comparability with previous studies on rhoticity in Inner Circle varieties (e.g., Nagy and Irwin, 2010; Piercy, 2012) as well as Expanding Circle Englishes (e.g., Kang, 2013), we identified 6 preceding vocalic environments, in particular the vowels in NEAR, SQUARE, LETTER, NURSE, START, and FORCE lexical sets.

With regard to the factor stress, the variant (r) in the elicited tokens was coded as occurring either in stressed or unstressed syllables. The coding of stress was based on the actual realization of stress in each test token rather than simply following the citation form of the preceding vowels. For instance, the function words for and or were coded as unstressed, even though their citation form, which contains the FORCE vowel, could lead one to categorize the vowel as stressed. The significant effect of stress has been reported in a number of studies on rhoticity in Inner Circle English varieties, such 
as Irwin and Nagy's (2007) research on Boston English and Piercy's (2012) study on Dorset English. Both of the studies have indicated that the stressed syllables favor rhoticity while the unstressed syllables disfavor it. Furthermore, Bonnici's (2010) study on Maltese English, an Outer Circle variety, also examined the influence of syllabic stress on (r) presence and showed a similar trend.

The last phonological factor tested was syllable structure. The tokens were coded based on the position of postvocalic /r/: (i) the coda position, which is followed by a heterosyllabic consonant as in nearly, (ii) word final position before a pause or a consonant-initial word (e.g., before), and(iii) before a tautosyllabic consonant, occurring either in the same morpheme as the rhotic sound (e.g., southern) or was separated from it by a morpheme boundary (e.g., villagers). It should be noted that syllable structure has also been shown to be an important linguistic factor conditioning (r). In Labov's (1972) department store study, for example, it has been demonstrated that speakers pronounced word-final $(\mathrm{r})$ in floor more frequently than the $(\mathrm{r})$ in consonant clusters such as fourth. Nagy and Irwin (2010) and Piercy (2012) also showed that (r) in the coda position was produced at a higher rate than (r) in consonant clusters.

\section{Results}

\subsection{Overall degree of rhoticity}

Table 5 shows the frequency of $(r)$ presence in all cases, suggesting that Chinese English represented by the English teachers in our study is only slightly rhotic at best (55.1\%). This pattern goes slightly in the direction of Kang's (2013) findings on Korean English, although Korean speakers in that study were shown to resort to rhotic realizations with a much higher frequency (73.9\%) than in the present study.

\begin{tabular}{l|ll|l}
\hline & r-full & r-less & Total \\
\hline $\mathrm{N}$ & 420 & 342 & 762 \\
$\%$ & 55.1 & 44.9 & 100 \\
\hline
\end{tabular}

Table 5: Overall distribution of (r) in Chinese English

Our finding however differs from what was previously shown for Yunnan English, which is based in the South of China. As noted above, Sundkvist and Gao (2016) focused primarily on variation in speech styles concerning this variety. Instead of presenting an overall degree of $(r)$ presence, they reported the percentage of (r) across three different speech types - interview (38.5\%), reading (45.1\%), and questionnaire (64.9\%). Since the present research investigated two similar speech styles that were included in the Yunnan English study, namely interview and reading, we can conclude that Yunnan English is rather non-rhotic compared with Chinese English, with the degree of rhoticity for both speech tasks lower than $50 \%$. A reasonable explanation for this distinction concerns the substrate language Mandarin, in particular the dialectal 
variation therein. As has been mentioned before, the Mandarin rhotic accent has been widely adopted in North China where a great majority of our participants originated from while Mandarin speakers from the South rarely produce the rhotic suffix since this feature is largely missing in the Southern Chinese dialects, which includes the Yunnan province. As such, the comparison between Yunnan English in Sundkvist and Gao (2016) and (Northern) Chinese English in our study makes a significant contribution to the role of dialectal variation in this domain although a direct comparison would be necessary to reveal the exact magnitude of the difference.

\subsection{Inter- and intra-speaker variability}

Inter- and intra- speaker variation of rhoticity in Chinese English is shown in Figure 1. As can be seen, the individual proportion of rhoticity varies across participants. More specifically, no Chinese English speaker was found to be either categorically rhotic or non-rhotic. The most rhotic speaker pronounced $98 \%$ of tokens as $/ \mathrm{r} /$-full, while the most $/ \mathrm{r} /$-less participant produced this variant as $/ \mathrm{r} /$-full only $27 \%$ of the time. The proportion of rhoticity for most participants ranges between 40 to $60 \%$. This pattern accords well with Sandkvist and Gao's findings (2015) on Yunnan English, which reports that six out of eight participants displayed rhoticity to "a variable although considerable degree" (p. 14), while the remaining two were considered mostly nonrhotic.

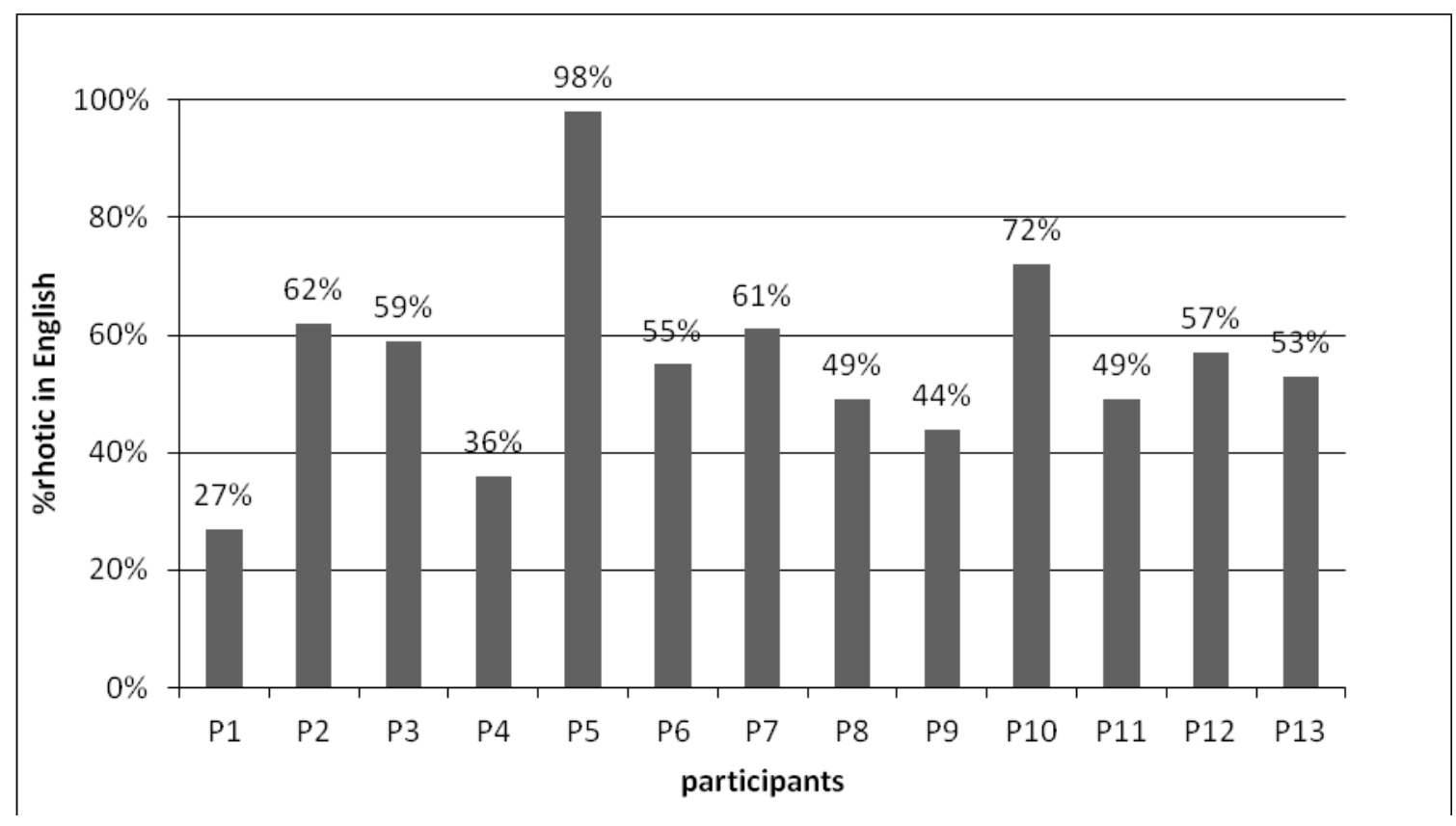

Figure 1: Individual distribution of (r) by Chinese English speakers; P stands for participant. 


\subsection{Multivariate analysis}

Table 7 presents the results of the multivariate analysis by a mixed effects model (best run, stepping-down) using the Rbrul package (Johnson, 2009) in R (R Core Team, 2016), with the presence of rhoticity as the application value. An alpha level of .05 was used for all statistical tests. Non-significant factor groups were not presented in the table. In particular, preceding vowel was the most significant phonological factor $(p<$ $0.001)$ conditioning rhoticity in Chinese English while both stress ${ }^{6}$ and syllable structure were not significant. More specifically, an inspection of the factor weights reveal that a preceding NEAR vowel was by far the strongest predictor of $(r)$ presence. This was followed by the SQUARE, LETTER, and NURSE contexts. The START and FORCE vowels were however disfavored rhoticity.

In terms of external factors, target norm turned out to be the most significant variable affecting rhoticity $(p=0.0018)$. Participants with American English as target norm strongly favored rhoticity while those with British English preference disfavored it. Furthermore, variation in speech styles was also shown to exert a significant albeit weak influence on rhoticity $(p=0.029)$. More specifically, the free speech task favored rhoticity while the passage reading task slightly disfavored it. Finally, we found a significant effect for the factor L1 rhoticity $(p=0.0023)$. This variable was operationalized by the degree of /r/-fullness that each participant showed in the Mandarin Chinese read aloud task, which was additionally verified by their place of origin. However, the directionality of the influence was contrary to our expectation. In particular, we predicted a positive correlation between the speakers' degree of rhoticity in L1 Mandarin and their L2 English. Instead, the participants in the rhotic Mandarin group strongly disfavored rhoticity in English. We will revisit this unexpected finding in our discussion below. 


\begin{tabular}{|c|c|c|c|c|}
\hline \multicolumn{5}{|l|}{ Best run, stepping down } \\
\hline Dependent variable & \multicolumn{4}{|l|}{$\mathbf{N}=762$} \\
\hline$=$ Presence of $/ \mathrm{r} /$ & \multicolumn{4}{|c|}{ Grand mean $=0.551$} \\
\hline & \multicolumn{4}{|c|}{ Intercept $=1.456$} \\
\hline & \multicolumn{4}{|c|}{ Degree of freedom = 11} \\
\hline Preceding Vowel $(\mathrm{P}<.0001)$ & Log odds & Factor weight & $\overline{\mathbf{N}}$ & \% rhotic \\
\hline NEAR & 1.08 & .75 & 91 & 71.4 \\
\hline SQUARE & 0.66 & .66 & 92 & 70.7 \\
\hline LETTER & 0.63 & .65 & 183 & 69.4 \\
\hline NURSE & 0.57 & .64 & 116 & 70.7 \\
\hline START & -0.97 & .28 & 104 & 33.7 \\
\hline FORCE & -1.97 & .12 & 176 & 26.1 \\
\hline Target Norm $(P=.0018)$ & Log odds & Factor weight & $\mathbf{N}$ & $\%$ rhotic \\
\hline American English & 1.20 & .73 & 428 & 61.2 \\
\hline British English & -1.20 & .27 & 334 & 47.3 \\
\hline Task $(P=.029)$ & Log odds & Factor weight & $\mathbf{N}$ & $\%$ rhotic \\
\hline Free speech & 0.33 & .59 & 294 & 55.4 \\
\hline Text & -0.33 & .41 & 468 & 54.9 \\
\hline$/ \mathrm{r} /$ in Mandarin $(\mathrm{P}=\mathbf{. 0 0 2 3})$ & Log odds & Factor weight & $\mathbf{N}$ & $\%$ rhotic \\
\hline nonrhotic & 1.00 & .73 & 446 & 62.3 \\
\hline rhotic & -1.00 & .27 & 316 & 44.9 \\
\hline
\end{tabular}

Table 6: Significant internal and external constraints on rhoticity in Chinese English

\section{Discussion}

In this section, we discuss 4 of our variables that turned out to be significant factors in the present study in light of the findings found in previous studies on the variant (r).

\subsection{Preceding vowel}

Among 3 phonological factors explored in the present study, the preceding vowel context was shown to be the only one that displays a statistically significant effect on rhoticity in Chinese English. The factor weights in Table 7 reveal the following hierarchy in terms of the strength of the vowel predicting / $\mathrm{r} /$-fullness. 
(1) Vowel hierarchy for the variant (r) in Chinese English:

NEAR $>$ SQUARE $>$ LETTER $>$ NURSE $>$ START $>$ FORCE

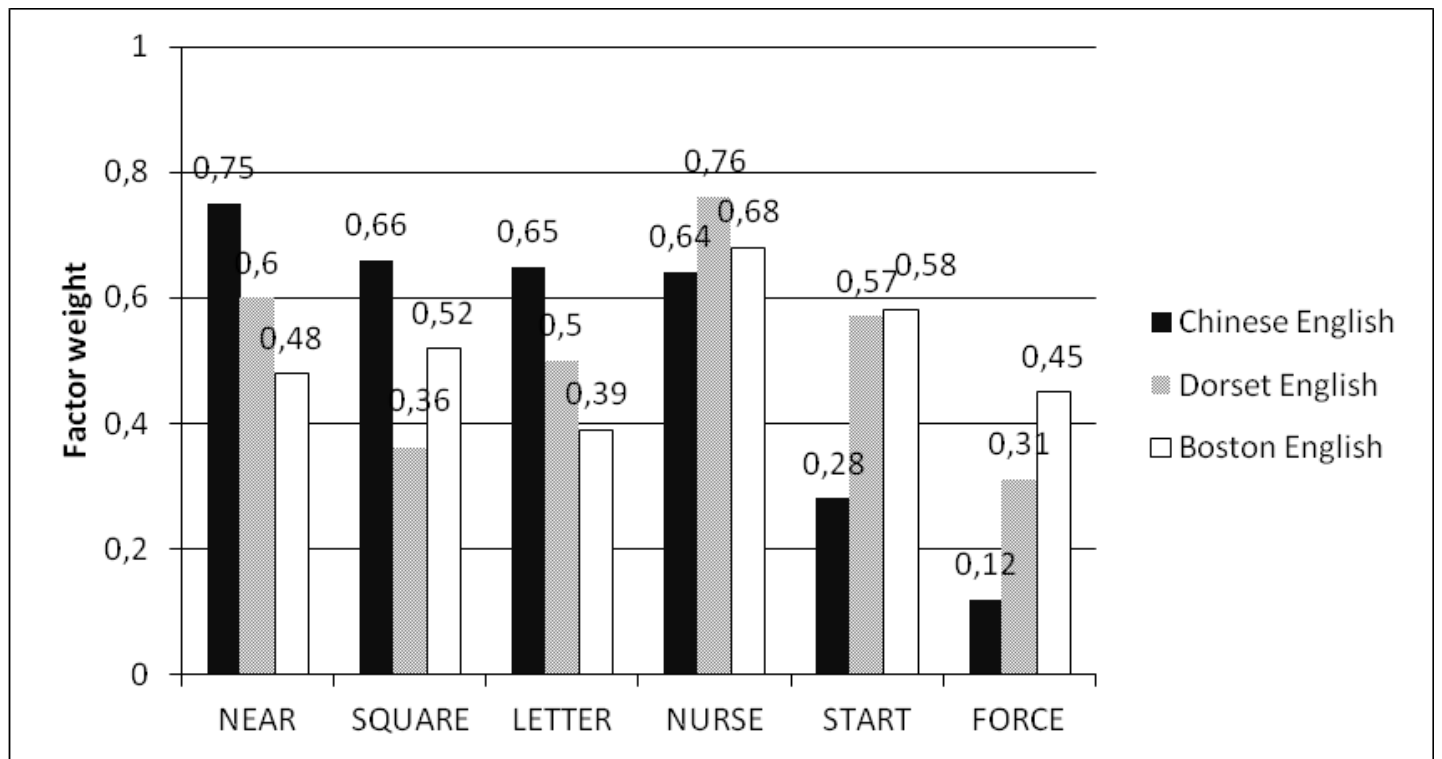

Figure 2: Comparison of the effect of preceding vowel on (r) presence in Chinese English and two Inner Circle varieties

Figure 2 displays a comparison of the effect of preceding vowel on (r) in Chinese English and the two Inner Circle varieties previously studied by Nagy and Irwin (2010) and Piercy (2012). Some commonalities can be observed concerning the effect of the preceding NEAR, NURSE, SQUARE, and FORCE vowels. While a preceding NEAR vowel favors rhoticity in both Chinese English and Dorset English, a preceding SQUARE vowel favors rhoticity in both Chinese English and Boston English. Furthermore, all three varieties favor a preceding NURSE vowel, which may indicate that the stressed schwa favors / $\mathrm{r}$-fullness in both Expanding Circle and Inner Circle Englishes. According to Nagy and Irwin (2010: 267), the NURSE vowel favors rhoticity more than the unstressed LETTER vowel in almost all studies about American English varieties. This finding, however, is in contrast to the present findings. As the figure shows, Chinese English speakers also favor rhoticity with a preceding LETTER vowel, while Boston English disfavoring it. No clear trend can however be seen for Dorset English. As Irwin and Nagy (2007: 141) notes, the divergent behavior of (r) by preceding environments in different varieties can be due to differences in vowel qualities across these varieties or due to differential coding of vowels in these studies. While this may be true, we suggest that the preference for rhotic realizations after the unstressed schwa in Chinese English finds a more straightforward explanation if we take into account perceptual similarity concerning the morphophonological properties of the L1 and those of L2. In particular, the above mentioned rhotic suffix in Mandarin bears a stark resemblance to English schwa $/ \mathrm{r} /$ sequences in that in both languages (i) these sequences occur in unstressed positions, (ii) they are mainly found at the end of a 
word, and (iii) they mostly function as a suffix (e.g., teacher, warmer, etc.). Since Mandarin Chinese rhoticity is primarily suffixal (i.e., it arises when the rhotic suffix is realized), we speculate that $/ \mathrm{r}$-coloring in English in the interlanguage of our participants has found a strong affinity to the rhotic suffix in their L1, thereby yielding a strong preference to render schwa $/ \mathrm{r} /$ as overly more rhotic than expected.

Another notable distinction between Chinese English and other two Inner Circle varieties concerns the preceding START vowel. Both Boston English and Dorset English favor (r) in this context while Chinese English disfavors it. The last noteworthy difference involves the preceding FORCE vowel. Although it is shown to be disfavored also in both Boston English and Dorset English, Chinese English displays a stronger dispreference than the two varieties. While we find no direct explanation for the distinction so far, the fact that both START and NORTH are dispreferred is on a par with Feagin's (1990: 137) findings in Anniston, Alabama, where back vowels were shown to disfavor [r] in comparison to front vowels.

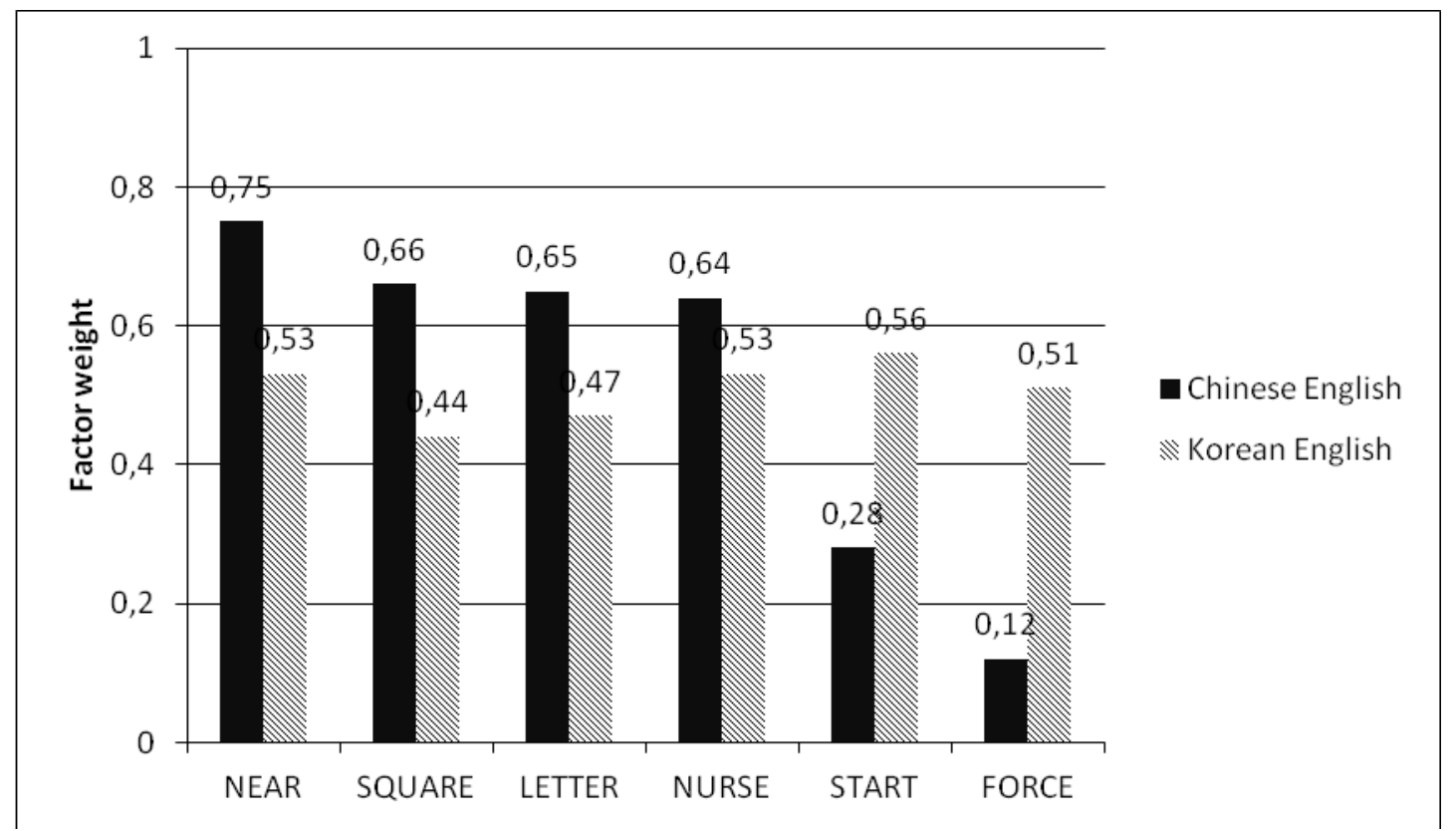

Figure 3: Comparison of the effect of preceding vowel on /r/ presence in Chinese English and Korean English

How do our findings compare to other Expanding Circle Englishes? Figure 3 displays the comparison of the factor weight of preceding vowel on rhoticity in Korean English (Kang 2013) and the present study. First of all, there is no distinct similarity between these two data sets, except for the preceding NEAR and NURSE vowels. In particular, both Korean English and Chinese English favor rhoticity with preceding NEAR and NURSE vowels. A preceding NEAR vowel strongly favors rhoticity in the present study while only slightly favoring rhoticity in Korean English. After the SQUARE and LETTER vowels, while Chinese English favors rhoticity, Korean English disfavors it in the same contexts. By contrast, in Chinese English, both START 
and FORCE strongly disfavor rhoticity while they slightly favor rhoticity in Korean English. Since the factor weight of all preceding vowels remains rather neutral in the range of 0.44-0.56 in Kang's results, it is however difficult to detect any robust vowel hierarchy in Korean English unlike what we found for Chinese English.

To conclude, the pattern observed in the present study bears more resemblance to Inner Circle English varieties rather than Korean English, which is also an EFL variety that can be assumed to form another important Expanding Circle variety in East Asia. One possible explanation for this difference in the two EFL varieties could be due to the stark differences in the proficiency levels of the speakers tested. Kang's study investigated Korean college students, who we assume to be less proficient and less stable in their English pronunciation than the participants recruited for the present study, who were English language professionals, more specifically college English teachers who use English regularly for teaching and communication purposes. To this end, the proficiency level of informants in the present study is closer to that of native English speakers in comparison to the Korean English learners in Kang's study. Accordingly, the patterning of the vowel preceding (r) in the present study is more similar to the one found in Inner Circle varieties compared with the Korean English variety.

\subsection{Target norm}

It should be remembered that the data concerning the participants' self-proclaimed target norm was collected based on the questionnaire. To further confirm whether their preference was consistent, an additional survey of language attitude on their preference for RP non-rhotic accent or American English rhotic accent was conducted via a 5-level Likert scale. Results show that our participants' language attitude and claimed target norms are completely consistent. As expected, target norm showed a significant effect on their rhoticity. Participants with American English as target norm produced more (r) tokens than those targeting British English. The present study is the first of its kind to investigate speakers' target norm as an influential factor determining rhoticity in Expanding Circle Englishes.

\subsection{Speech style}

Variation in speech styles also plays a significant role in constraining rhoticity in the present study. Results indicate that Chinese English speakers produced more rhotic sounds in free speech than in the reading task. A possible explanation for this result would be the difference in the level of formality between the two tasks. To that end, we assume that the reading task induced a more formal style than the free speech task. As such, our Chinese English speakers can be said to produce more rhotic tokens in the informal style than in the formal one. Indeed, this pattern echoes the production context of rhotic suffixes in their L1 Mandarin. As mentioned before, the rhotic suffix ' $L$ ' in Mandarin Chinese is known to be pronounced more frequently in informal speech than in formal situations. It could be concluded that the stylistic choices concerning the 
rhotic suffix in Chinese speakers' L1 Mandarin has a potential impact on the realization of (r) variant in Chinese English.

The direction of stylistic influence on rhoticity in our study is however in contrast to what Sundkvist and Gao (2016: 53-54) reported for Yunnan English. In particular, Yunnan English participants showed the lowest degree of rhoticity (38.5\%) in the most informal interview task while producing much higher rates of rhoticity in tasks that triggered more formal styles $(45.1 \%$ in the reading task and $64.9 \%$ in the most formal dialectological-style questionnaire task). The non-rhotic Mandarin spoken by Yunnan English speakers may account for this difference. As discussed above, Yunnan province is located in South China, where the rhotic suffix is rarely used. As a result, we conclude that the productions of Yunnan English speakers could not have been affected by the same stylistic effect as those of the rhotic Mandarin speakers in our study.

\subsection{Rhoticity in L1}

We predicted that since Mandarin Chinese is more rhotic in North China, Chinese English speakers from such rhotic dialect backgrounds would exhibit a higher proportion of $/ \mathrm{r} /$-fullness in English than Mandarin speakers from non-rhotic dialect backgrounds. We employed a Mandarin reading task to evaluate our participants' degree of rhoticity in their L1. We resorted to a categorical distinction in L1 rhoticity (i.e., non-rhotic vs. rhotic) since 8 out of 13 participants did not realize the rhotic suffix in at least 8 of the 10 target Mandarin Chinese words, which we took to be a good indicator of strong non-rhoticity in the L1. Accordingly, we labeled these participants as "non-rhotic". The remainder $(n=5)$ was automatically categorized into the rhotic Mandarin group. Although L1 rhoticity was a significant factor in the model, ${ }^{7}$ the variable target norm exerted a greater influence on the production of (r), as discussed above. We suggest that since college English teachers have years of experience in learning and teaching English, their English speech patterns are less likely to be subject to L1 influence, thereby exhibiting more convergence with the phonological patterns of the respective target norms. We speculate that the substratum language effect may be stronger in the accents of EFL learner varieties than more stable types of English found in the Expanding Circle.

\section{Conclusion and outlook}

Although the speakers of the EFL variety investigated here form only a small portion of a massive body of EFL speakers in East Asia, it is representative of the type of English taught and used at EFL instructional settings in the region. Consequently, the English represented by our college teachers is acquired by an ever-growing learner population in China, which will eventually yield masses of highly proficient users of English in the region. To that end, we explored a relatively small but quite instructive aspect of this emerging variety, the degree of rhoticity, and showed the way internal and external factors constrain the production of $(r)$ on the basis of experimental data collected from 
college English teachers in China. Our results suggest that Chinese English represented by these teachers is slightly rhotic and thus sounds closer to American English accent, albeit with considerable inter- and intra- speaker variability. The preceding vowel environment was shown to be the most significant phonological factor conditioning the production of the rhotic variant. Specifically, a preceding NEAR vowel was found to be the strongest predictor of (r) in Chinese English while the preceding FORCE vowel strongly disfavored rhoticity. Upon closer inspection, we showed that the preceding vowel pattern observed to condition rhoticity in our study is strikingly closer to the pattern reported in previous studies on Inner Circle varieties than Expanding Circle Englishes. In and of itself, this is a clear indication that we have dealt with an already established, relatively stable nonnative variety, which is likely to form one of the important sources of input and serve as a salient model of English pronunciation for incoming English learners in China.

What does the systematic emergence of similar structural factors in this nonnative variety, which also modulate the patterning of rhoticity in other English varieties imply for the emergence of novel sound patterns and the way it should be studied? Our study has shown that the variety under investigation here permeates the classic boundaries of the field of Second Language Acquisition, where the nature and sources of nonconvergence between nonnative and native users dominate various lines of empirical inquiry and consequently shape theoretical approaches. What we have instead observed here is a systematic variability that is on the one hand reminiscent of native varieties of English, and seemingly more stable and complex than that found in SLA studies on the other. This resonates with the Dynamic Systems Theory (DST) approach to multilingualism and second language acquisition, where languages (including second or additional languages) are viewed as complex and dynamic systems, which are argued to be in a constant flux (Herdina and Jessner, 2002; De Bot et al., 2007). For instance, De Bot et al. (2007: 19) suggest that "through iterations of simple procedures that are applied over and over again with the output of the preceding iteration as the input of the next, complexity in language emerges". Our study provides an instructive case to this view, where the target norm turned out to be the most significant sociolinguistic constraint determining (r), crucially overriding cross-linguistic influence effects. In particular, although the patterning of rhoticity in Chinese English was modulated to some extent by the L1 of the speaker, the overall degree of rhoticity for these highly proficient English speakers was more strongly determined by the target norm. This outcome accords with previous research on second language phonological grammars, which has time and again suggested that such nonnative phonological grammars are better understood in conjunction with natural laws of phonetics, perceptual and articulatory constraints on speech processing, as well as a range of cognitive, psychological and social phenomena such as attitudes, motivation and age (see Altmann and Kabak, 2010; Moyer, 2013 for reviews). However, such factors are not solely reserved for nonnative systems since a large array of sociophonetic research has suggested that similar social and psychological factors also govern variability and change within and across lifespans. Accordingly, Kabak (to appear) expands the study 
of phonological patterns to all spheres and facets of language behavior since they are uniformly governed by the same set of phonetic, cognitive and social constraints although their weights and magnitude of influence may differ from one another. Arguing against the dichotomy between natural and unnatural patterns of sound change (e.g., Blevins, 2006), Kabak shows that the same external and internal network of variables that operates in diachrony also operates in second language acquisition of phonological systems. To that end, combining diachronic and psycholinguistic evidence, he offers a Dynamic Equational Approach towards sound patterns. The central tenet of the approach is that all sound patterns (unless they are highly fossilized) are characterized by a degree of gradience and variability, and that this gradience arises by a complex interplay of both language-internal and language-external factors with phonological variants in all facets and shapes of language evolution and change. Here, the term equation encapsulates both an empirical dimension as well as metaphorical extension. That is, it reflects not only the complex relations among the many variables involved in the generation of a sound pattern, but also pushes the idea that sound patterns are best explored when all other variables that co-determine the shape, direction, and magnitude of sound structure are treated as equally unknown as in a mathematical equation. Essentially, the assigned values to the variables within an equation lead to a solution. Furthermore, "equation" resonates equality in treating all forms of language behavior as uniformly real such that phonological variation and change due to language contact (be it realized in loanword phonology, first language attrition, and the emergence of interlanguages or creoles, etc.) should be viewed as natural. Accordingly, different forms of language contact are essentially different reincarnations of a dynamic interaction of linguistic systems that are expected to interact with one another, each being subject to the same set of laws. The current study provides a compelling addition to the Dynamic Equational Model in that the same set of linguistic and extra-linguistic constraints that underlie the patterning of rhoticity in both Inner Circle and Outer Circle Englishes (e.g., vowel context, target norm) and in the substrate language (e.g., dialectal rhotic-nonrhotic variability, stylistic variation) have also been observed to be at work in an Expanding Circle variety, albeit with a different ranking and magnitude that are commensurate with the "noise" that the complex interaction factors that SLA and language contact situations bring about.

Before we conclude, a few words are in order concerning the weaknesses of our study that we hope to guide future research. We used only a reading task to confirm the levels of rhoticity in the L1 of our participants. Provided that rhoticity in Mandarin is sensitive to the variation in the formality of speech styles, a simple formal reading task may have resulted in an overall decline of the presence of $/ \mathrm{r} /$-full tokens in Mandarin. Future studies should thus employ a variety of speech elicitation tasks that tap different styles of speech in order to reach a more comprehensive score of participants' rhoticity levels in their L1. One of the empirical contributions of our study, despite this weakness, is that inherent variability within the L1 may mirror in the extent of variability in the L2. That is, transfer due to cross-linguistic influence does not always 
take place in a whole-sale manner but rather it may reflect the gradient influence of constraints already existing within the L1.

Another problem concerns the test population we studied. In particular, we tested college English teachers in China who were considered to be highly proficient and representative Chinese English speakers. In apparent time, Chinese English will grow by the number of highly proficient users of English, who are currently EFL students (of these teachers). Thus, future research should include a direct comparison between Chinese EFL learners of English and the norm providers, i.e., English language professionals and teachers, as this may contribute a broader understanding of how accentual norms perpetuate and how phonological input turns into intake by learners.

All in all, the significance of the present paper stems from the fact that it provides a comprehensive empirical study of rhoticity in Chinese English and extends the inquiry into both linguistic and extra-linguistic constraints. It contributes to our understanding of the conditions that modulate (r) occurrence in Expanding Circle Englishes, a research area that is severely understudied in comparison to English varieties in the Inner and the Outer Circle. In addition, as rhoticity is considered one of the most notable variables classifying world Englishes, the phonological findings also provide a valuable piece to the burgeoning puzzle of the typology of World Englishes. Since the research on Chinese English phonology is still in its infancy, we expect our study to draw more attention to the scarcity of empirical work on the linguistic and sociolinguistic aspects of this thriving variety. Finally, we hope that our study hinted at a necessary paradigm shift in our current understanding of and approach to World Englishes such that the field should be more directly informed by psycholinguistic and sociolinguistic theories, approaches and insights from the field of Second Language Acquisition. Thus, we suggest that an "L2 acquisitionist turn" is inevitable in the conceptualization of alternative Englishes.

\section{Notes}

1. Whenever necessary, we will use / $\mathrm{r} /$ to mark the rhotic phonemic category in English although there is considerable variation in its exact phonetic realization across English varieties as well as in different phonological contexts within individual varieties (see Gimsom and Cruttenden, 1994: 186-190).

2. Following the sociolinguistic research conventions, we interchangeably refer to the variable realization of postvocalic /r/ as the "variant (r)" throughout the paper.

3. English spoken or written by people from mainland China has not yet found a consistently used term in the field. Citing various sources, $\mathrm{He}$ and $\mathrm{Li}$ (2009: 71) list 'Chinglish', 'Chinese English', 'Sinicized English', as well as 'China English' as labels previously used in the literature. Although all of the participants in the present study had been living in North China at the time of testing, we will use 'Chinese English' to refer to their variety of English since they originated from various places in China.

4. Indeed, language professionals who teach and test English language skills in EFL contexts can be said to create "codification" practices which serve as the standard for English education. In this vein, Shim (1999: 250-256), for example, argues that what is learned in 
Korean schools is different from the target norm, American English, and observes that Korean EFL users in the country now share a set of unique lexico-semantic, pragmatic and grammatical rules, which feature in English textbooks used in Korean high schools.

5. We chose $44 / 45$ as the boundary to reflect the mean of the age range (31-59) we had in our population. While this cut allowed us to have two groups with a relatively balanced number of participants in each, it also constitutes a sensible division from the point of view of major technological, social and political changes that were incipient in the 1990s, an era characterized by, among others, the rise of multiculturalism, social media and the World Wide Web, which arguably exerted a significant influence on the spread of English around the world (we assumed that those teachers younger than 45 at the time of testing were university students or in the early phases of their professional training in the 1990s and beyond).

6. The fact that stress did not come out significant is perhaps not surprising given that stress was highly co-linear with vowel quality.

7. It should be noted again that the fact that we observed a high rate of rhoticity with the LETTER vowel in our sample can be attributed to a potential cross-linguistic influence from Mandarin Chinese, where the rhotic suffix is phonetically similar to English schwa /r/.

\section{Acknowledgements}

The authors would like to thank the teachers who participated in this study at the North China Institute of Science and Technology, as well as Marie-Christin Himmel at the University of Würzburg and the two anonymous reviewers for their helpful comments.

\section{References}

Altmann, Heidi and Barış Kabak (2010): "Second language phonology". In N. Kula et al., eds., Continuum Companion to Phonology. London: Continuum, 298-319.

Becker, Kara (2009): “/r/ and the construction of place identity on New York City's Lower East Side”. Journal of Sociolinguistics, 13(5): 634-658.

Becker, Kara (2014): “(r) we there yet? The change to rhoticity in New York City English". Language Variation and Change, 26(2): 141-168.

Blevins, Juliette (2006): "New perspectives on English sound patterns: 'Natural' and 'Unnatural' in Evolutionary Phonology". Journal of English Linguistics, 34: 6-25.

Bonnici, Lisa Marie (2010): Variation in Maltese English: The Interplay of the Local and the Global in an Emerging Postcolonial Variety. University of California, Davis.

Chand, Vineeta (2010): "Postvocalic (r) in urban Indian English". English World-Wide, 31(1): $1-39$.

Chen, Ping (1999): Modern Chinese: History and Sociolinguistics. Cambridge University Press.

Gimson, Alfred Charles and Alan Cruttenden (1994): Gimson's Pronunciation of English. $5^{\text {th }}$ edition. London-New York-Sydney-Auckland: Edward Arnold.

De Bot, Kees, Wander Lowie and Marjolijn Verspoor (2007): "A dynamic systems theory approach to second language acquisition". Bilingualism: Language and Cognition, 10(1): 721. 
Deterding, David (2006): "The North Wind versus a Wolf: Short texts for the description and measurement of English pronunciation". Journal of the International Phonetic Association, 36(2): 187-196.

Deterding, David (2007): Singapore English. Edinburgh University Press.

Duanmu, San (2007): The Phonology of Standard Chinese. Oxford University Press.

Eberhardt, Maeve and Corinne Downs (2015): "(r) You Saying Yes to the Dress? Rhoticity on a Bridal Reality Television Show". Journal of English Linguistics, 43(2): 118-142.

Feagin, Crawford (1990): "The dynamics of a sound change in Southern States English: From R-less to R-ful in three generations". In Jerold A. Edmonson, Crawford Feagin, and Peter. Mühlhäusler, eds., Development and Diversity: Linguistic Variation across Time and Space Dallas: Summer Institute of Linguistics/ University of Texas at Arlington, 29-146.

Fowler, Joy (1986): The Social Stratification of $(r)$ in New York City department stores, 24 years after Labov. Unpublished Ms, pp. 268.

Giegerich, Heinz J. (1992): English Phonology: An Introduction. Cambridge: Cambridge University Press.

Gut, Ulrike B. (2004): "Nigerian English: Phonology". In E.W. Schneider et al., eds., A Handbook of Varieties of English. Volume 1: Phonology. Berlin: Mouton de Gruyter, 813830.

Hansen, Jette G. (2001): "Linguistic constraints on the acquisition of English syllable codas by native speakers of Mandarin Chinese". Applied Linguistics, 22(3): 338-365.

Hartmann, Dieter and Sabine Zerbian (2010): "Rhoticity in Black South African English-a sociolinguistic study". Southern African Llinguistics and Applied Language Studies, 27(2): 135-148.

Hay, Jennifer and Alhana Clendon (2012): “(Non)-rhoticity: Lessons from New Zealand English". In T. Nevalainen and E.C. Traugott, eds., The Oxford Handbook of the History of English. Oxford: Oxford University Press, 761-772.

He, Deyuan and David Li (2009): "Language attitudes and linguistic features in the "China English'debate". World Englishes, 28(1): 70-89.

Herdina, Philip and Ulrike Jessner (2002): A Dynamic Model of Multilingualism: Perspectives of Change in Psycholinguistics, vol. 121. Clevedon: Multilingual Matters.

Irwin, Patricia and Naomi Nagy (2007): "Bostonians /r/ speaking: A quantitative look at (R) in Boston". University of Pennsylvania Working Papers in Linguistics, 13(2): 135-147.

Johnson, Daniel Ezra (2009): "Getting off the GoldVarb standard: Introducing Rbrul for mixedeffects variable rule analysis". Language and Linguistics Compass, 3(1): 359-383.

Kabak, Barış (forthcoming): "A dynamic equational approach to sound patterns: The (un)stability of English dental fricatives illustrated". In B. Busse and R. Möhlig-Falke, eds., Patterns in Language and Linguistics. Mouton de Gruyter (upcoming).

Kachru, Braj B, ed. (1982): The Other Tongue: English Across Cultures. Urbana, IL: University of Illinois Press.

Kachru, Braj B. (1985): "Standards, codification and sociolinguistic realism: The English language in the Outer Circle". In Randolph Quirk and H. G. Widdowson, eds., English in the World: Teaching and Learningh the Language and Literatures. Cambridge: Cambridge University Press, 11-30.

Kang Hyeon-seok (2013): "Internal and external constranits on rhoticity in Korean English". The Sociolinguistic Journal of Korea, 21(2): 1-27.

Labov, William (1966): The Social Stratification of English in New York City, Washington, DC: Center for Applied Linguistics. 
Labov, William (1972): Sociolinguistic Patterns (No. 4). Philadelphia: University of Pennsylvania Press.

Llamzon, Teodoro A. (1997): “The phonology of Philippine English”. In M.L.S. Bautista, ed., English is an Asian Language: The Philippine Context. Sydney: The Macquarie Library, 4148.

Love, Jessica and Abby Walker (2012): "Football versus football: Effect of topic on $/ \mathrm{r} /$ realization in American and English sports fans". Language and Speech, 56(4): 443-460.

Mahboob, Ahmar and Nandra H. Ahmar (2004): "Pakistani English: Phonology". A Handbook of Varieties of English: A Multimedia Reference Tool, 1003-1015.

Mather, Patrick-André (2012): "The social stratification of / $\mathrm{r} /$ in New York City: Labov's department store study revisited". Journal of English Linguistics, 40(4): 338-356.

Melchers, Gunnel and Philip Shaw (2003): World Englishes. London: Arnold.

Miller, Corey A. (1998): "R-lessness in Philadelphia". In C.A. Moyer, ed., Sociolinguistics, Language and Society. New Delhi, India: Sage, 79-96.

Moyer, Alene (2013): The Phenomenon of Non-Native Speech. Cambridge, UK: Cambridge University Press.

Nagy, Naomi and Irwin, Patricia (2010): "Boston (r): Neighbo (r) s nea (r) and fa (r)". Language Variation and Change, 22(2): 241-278.

Piercy, Caroline (2012): "A transatlantic cross-dialectal comparison of non-prevocalic /r/". University of Pennsylvania Working Papers in Linguistics, 18(2).

Poedjosoedarmo, Gloria (2000): “A description of the English pronunciation of young educated Singaporeans: A study in multidimensional variation". The English Language in Singapore: Research on Pronunciation, 65-75.

R Core Team (2016): R: A Language and Environment for Statistical Computing. R Foundation for Statistical Computing, Vienna, Austria. ISBN 3-900051-07-0, URL http://www.Rproject.org/

Salbrina, Sharbawi and David Deterding (2010): "Rhoticity in Brunei English". English WorldWide, 31(2): 121-137.

Schmied, Josef (2006): "East African Englishes". In Braj B. Kachru, Yamuna Kachru and Cecil L. Nelson, eds., The Handbook of World Englishes. Oxford: Blackwell, 188-202.

Schneider, Edgar W. (2003): "The dynamics of New Englishes: From identity construction to dialect birth". Language,79(2): 233-281.

Schneider, Edgar W. (2007): Postcolonial English: Varieties around the World. Cambridge University Press.

Setter, Jane, Cathy S. P. Wong and Brian H.S. Chan (2010): Hong Kong English. Edinburgh: EUP.

Shim, Rosa Jinyoung (1999): "Codified Korean English: process, characteristics and consequence". World Englishes, 18(2): 247-258.

Sullivan, Anthea E. (1992): Sound Change in Progress: A Study of Phonological Change and Lexical Diffusion, with Reference to Glottalization and r-loss in the Speech of Some Exeter Schoolchildren, vol. 17. Exeter: University of Exeter Press.

Sundkvist, Peter and Man Gao (2016): "Rhoticity in Yunnan English". World Englishes, 35(1): 42-59.

Tan, Chor Hiang and Anthea Fraser Gupta (1992): "Post-vocalic /r/ in Singapore English". York Papers in Linguistics, 16: 139-152.

Tan, Ying Ying (2012): "To $r$ or not to $r$ : Social Correlates of $/ \boldsymbol{d} /$ in Singapore English". International Journal of the Sociology of Language, 218: 1-24. 
Thomas, Erik R. (2007): "Phonological and phonetic characteristics of African American vernacular English". Language and Linguistics Compass, 1(5): 450-475.

Trudgill, Peter and Jean Hannah (1994): International English: A Guide to Varieties of Standard English. London: Arnold.

Villard, Sarah (2009): "Postvocalic /r/ in the Upper Valley of Vermont and New Hampshire". Paper presented at NWAV 38, Ottawa.

Wells, John C. (1982): Accents of English, vol. 1. Cambridge: Cambridge University Press.

\section{Appendix 1 Questionnaire}

\section{College and university English teacher questionnaire}

We would like to ask you to help us by answering the following questions concerning foreign language learning and teaching. This is not a test so there are no "right" or "wrong" answers. We are interested in your personal opinion. Please give your answers sincerely as only this will guarantee the success of the investigation. Thank you very much for your help!

I. Background information

1. Your gender? male/ female

2. How old are you (in years)?

3. How old were you when you started learning English?

4. How old were you when you started teaching English?

5 . Where did you grow up? Where is your hometown? (province, city, town)

6. What Chinese dialect(s) do you speak besides Mandarin?

7. What foreign language(s) can you speak besides English?

8. Do you have any experience abroad? If yes, please indicate the country and length of residence.

9. Which kind of Standard English do you prefer to speak and teach, British English or American English?

10. Which kind of media do you regularly have exposure to?

American English media (American TV and films, VOA, etc.)

British English media (BBC News, British TV and films, etc.)

Both

Others (CCTV_news, TED, etc.), 


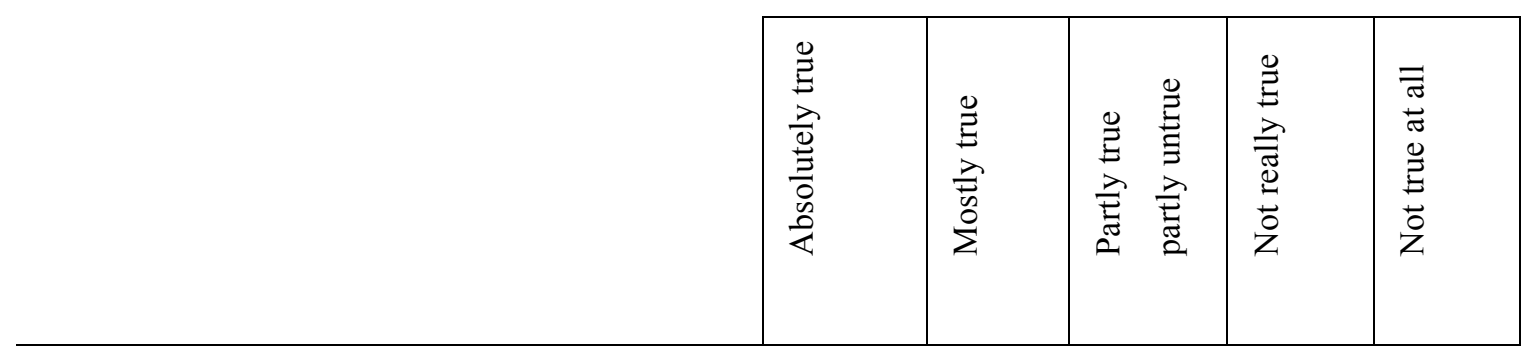

II. Now there are going to be statements some people agree with and some people don't. I would like to know to what extent they describe your own feelings of situation. After each statement you'll find five boxes, please put a ' ' in the box which best expresses how true the statement is about your feelings or situation. 


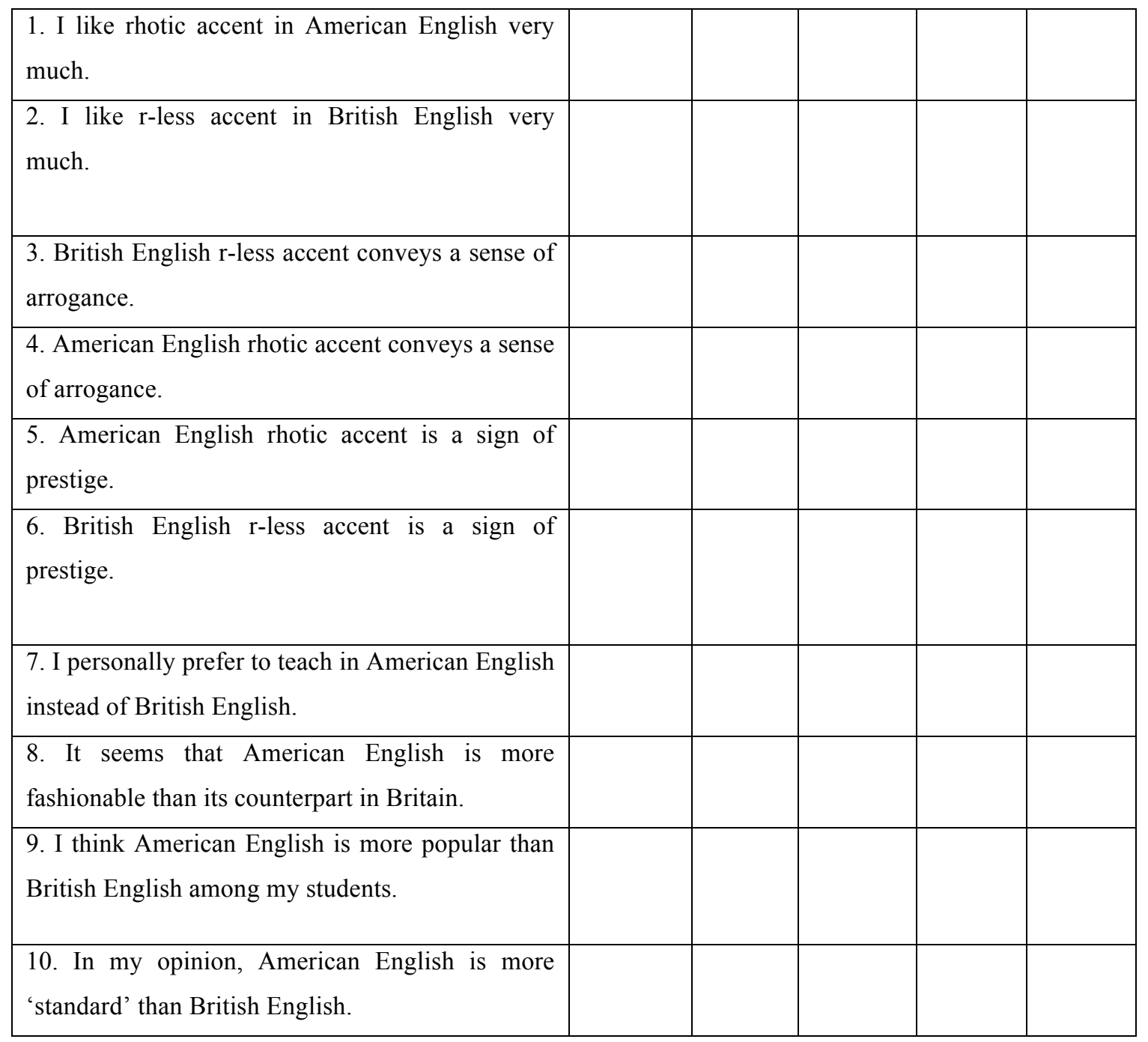

THANK YOU VERY MUCH -- WE REALLY APPRECIATE YOUR HELP! 